\title{
THE INTERACTION OF N-OCTANOHYDROXAMATE WITH CHRYSOCOLLA AND OXIDE
}

\section{COPPER SURFACES}

\author{
G.A. Hope ${ }^{a, *}$, A.N. Buckley ${ }^{b}$, G.K. Parker ${ }^{a}$, A. Numprasanthai ${ }^{a}$, R. Woods ${ }^{a}, J$ McLean $^{c}$ \\ a. Queensland Micro- and Nanotechnology Centre, Griffith University, Nathan, QLD, 4111, Australia. \\ b. School of Chemistry, University of New South Wales, Sydney, NSW, 2052, Australia. \\ c. Axis House, Camberwell, VIC, 3124, Australia. \\ * Corresponding author. Tel.: +617 373 53656; fax: +617 373 57773; E-mail address: \\ g.hope@griffith.edu.au
}

\section{ABSTRACT}

Vibrational spectroscopy and XPS have been used to investigate the interaction of n-octanohydroxamate with the surfaces of chrysocolla and other oxide copper minerals, as well as with the native oxide on copper metal. XPS investigations of low collector coverage at $\mathrm{pH} 9.5$ confirmed that copper hydroxamate was formed at the mineral/collector interface. Multilayers were formed at all surfaces investigated, probably with minor $(\sim 15 \%)$ co-adsorption of hydroxamic acid. The coverage at conditioned chrysocolla surfaces tended to be less uniform than coverage at the 'well-defined' oxide minerals. There was also some evidence for the formation of an $\mathrm{Al}$ hydroxamate species at the chrysocolla surface.

Keywords: Mineral processing, Flotation collectors, Oxide ores.

\section{Introduction}

The oxide copper minerals are an important copper resource. These are found in the weathered regions of most copper sulfide ore bodies. The overlaying oxide ore is usually stockpiled after it is removed from the sulfide lode and left unprocessed as the sulfide ore is simpler to recover by conventional flotation procedures and thus, more attractive to the mine operator. Oxide ore can be concentrated using flotation or, if it has a low acid demand, it may be economic to acid heap leach the stockpile. For ore with high acid requirements, 
either controlled potential sulfidization (CPS), followed by flotation, or direct flotation using hydroxamate reagents (Lee et al., 2009) are more attractive options.

It is generally recognised that hydroxamates are good collectors for the 'well-defined' oxide copper minerals, such as malachite (Lee et al., 1998). Most well-defined oxide minerals exhibit flotation maxima at pHs within \pm 0.5 of the pKa of the hydroxamate (Fuerstenau, 2007). We have previously proposed a mechanism for the interaction of n-octanohydroxamate collector with the surface of oxide $\mathrm{Cu}$ minerals based on photoelectron spectra for hydroxamate adsorbed on the native oxide layer of air-exposed $\mathrm{Cu}$ metal and on sulfide minerals (Parker et al., 2012a, b). Both the multilayer and the initially adsorbed hydroxamate were present as an enolate (thus, strictly speaking, making it hydroximate) and, in the absence of multilayer $\mathrm{Cu}$ (hydroxamate), the $\mathrm{N}$ in each chemisorbed hydroxamate interacts with a $\mathrm{Cu}$ in the oxide surface; i.e., initially, the chemisorbed hydroxamate is oriented parallel to the surface rather than 'upright' so that both hydroxamate $\mathrm{O}$ atoms can interact with one $\mathrm{Cu}$ and the hydroxamate $\mathrm{N}$ can interact with another $\mathrm{Cu}$. For the oxide $\mathrm{Cu}$ substrates investigated, the onset of multilayer formation appeared to occur in patches before a uniform chemisorbed monolayer had been completed.

Chrysocolla is a significant oxide copper resource. The chemical composition of chrysocolla is generally accepted as $\mathrm{Cu}_{2-\mathrm{x}} \mathrm{Al}_{\mathrm{x}}(\mathrm{OH})_{4} \mathrm{H}_{2-\mathrm{x}} \mathrm{Si}_{2} \mathrm{O}_{5} \cdot \mathrm{nH}_{2} \mathrm{O}$, with $\mathrm{x}<1$. The mineral usually appears amorphous in $\mathrm{X}$-ray diffraction measurements, and this has been attributed to crystallites that are too small to give rise to a diffraction pattern. The description of the mineral structure has varied from a $\mathrm{Cu}$ silicate phase dispersed in an amorphous silica hydrogel, to predominantly cupric hydroxide, amorphous silica and water (Farges et al., 2006). The latter description was based mostly on $\mathrm{Cu}$ K-edge X-ray absorption fine structure (XAFS) spectra from powdered samples finely ground in water. McKeown (1994) had interpreted his XAFS data to indicate the presence of $\mathrm{CuO}_{4}$ units, similar to those in tenorite $(\mathrm{CuO})$ or dioptase $\left(\mathrm{CuSiO}_{3} \cdot \mathrm{H}_{2} \mathrm{O}\right)$, with the likely arrangement of these units in strips. Neither XAFS investigation was consistent with the presence of $\mathrm{Cu}_{2} \mathrm{O}$.

Although chrysocolla is a poorly defined mineral, hydroxamate has been shown to be an effective collector for it, at least at the laboratory scale, with optimum recovery at $\mathrm{pH} \sim 6.5$ (Peterson et al., 1965; 
Danilova et al., 1975; Fuerstenau and Pradip, 1984). Raghavan and Fuerstenau (1977) reported that difficulties associated with the flotation of chrysocolla in practice were due to its microporous structure. Fuerstenau and Pradip (1984) reviewed the literature available on the use of hydroxamates in flotation and put forward a mechanism involving adsorption on oxide surfaces. In their Hallimond tube flotation studies they found maximum flotation occurred at $\mathrm{pH} \sim 6$, which they attributed to hydrolysis of lattice cations in the mineral (Fuerstenau and Pradip, 1984). Contact angle studies subsequently undertaken showed maximum contact angle at $\mathrm{pH} \sim 9$ (Fuerstenau et al., 2000). Herrera-Urbina et al. (2010) investigated chrysocolla flotation and noted that chrysocolla solubility increased sharply below pH 6 but remained relatively constant above this value. They proposed that optimal recovery of chrysocolla by flotation with n-octanohydroxamate required minimising the dissolution of copper, such as through dry grinding of the ore, followed by short conditioning with reagents prior to flotation at $\mathrm{pH} \sim 6.5$ (Herrera-Urbina et al., 2010). Recovery at $\mathrm{pH} \sim 9.5$ was almost as high as at $\mathrm{pH} 6.5$, even after longer conditioning times, as loss of $\mathrm{Cu}$ from the mineral was not significant (Herrera-Urbina et al., 2010).

In light of those findings, we have compared the collector coverage on chrysocolla with that on some 'well-defined' oxide $\mathrm{Cu}$ minerals after conditioning at $\mathrm{pH}>9$ to identify whether there are significant differences. We also report on whether hydroxamic acid is significantly co-adsorbed at $\mathrm{pH} \sim 9.5$. An extended characterisation of chrysocolla prior to, as well as following, its conditioning in hydroxamate collector is also included to shed further light on the nature of this poorly-defined mineral.

\section{Experimental methods}

\subsection{Reagents and mineral specimens}

Electrolyte and reagent solutions were made with Analytical Reagent (AR)-grade chemicals and doubly de-ionised (DDI) water. Potassium hydrogen n-octanohydroxamate was supplied by Axis House, recrystallised from methanol and dried in air before use. The n-octanohydroxamic acid was precipitated by neutralising a concentrated, alkaline $(\mathrm{KOH})$ solution of potassium hydrogen n-octanohydroxamate with sulfuric acid, filtered, washed with DDI water and dried in air. The sample was then recrystallised from 
methanol and dried in air before investigation. Copper salts were synthesised as described previously (Hope et al., 2011a).

Natural malachite and azurite samples were obtained from mine sites in the Democratic Republic of Congo, Canada and Morocco. Chrysocolla, sourced from Clifton AZ, was purchased as a hand-picked lump from Tucson Mineral and Gem World, Tucson AZ. The pseudomalachite was sourced from the West Bogan Mine, Tottenham, NSW.

\subsection{Vibrational spectroscopy}

Raman studies were conducted on a Renishaw InVia spectrometer. $632.8 \mathrm{~nm}$ excitation from a HeNe laser was used and the scattered light was detected with a Peltier-cooled CCD detector with spectral resolution $\sim 2 \mathrm{~cm}^{-1}$. The laser and scattered light were usually focused through a $\mathrm{x} 50$ Leica $\mathrm{N}$ Plan lens (NA=0.75). Raman spectra were calibrated using the $520 \mathrm{~cm}^{-1}$ silicon band. Spectral manipulations such as baseline adjustment, smoothing and normalisation were performed either with the Renishaw WiRE 3.2 software or with GRAMS32AI software (Galactic Industries, Salem, NH, USA). Fourier transform infrared (FT-IR) spectra were collected on a Thermo Nicolet Nexus FT-IR spectrometer equipped with EverGlo IR source optics which provides a stabilised signal and $0.5 \mathrm{~cm}^{-1}$ resolution. The spectrometer had a DTGS detector with $\mathrm{KBr}$ window and $\mathrm{Ge}$ on $\mathrm{KBr}$ beamsplitter. Spectra were acquired in the range of $4000-500$ $\mathrm{cm}^{-1}$.

\section{$2.3 X$-ray photoelectron spectroscopy}

Most X-ray photoelectron spectra were collected from a surface of single piece specimens of area approximately $5 \mathrm{~mm}$ x $5 \mathrm{~mm}$ rather than mineral particles of floatable size. Each surface was abraded until relatively smooth to the unaided eye before conditioning in a saturated aqueous $\mathrm{KH}$ (n-octanohydroxamate) ${ }_{2}$ solution, rinsing with water, and subsequent characterisation by XPS at either $\sim 150 \mathrm{~K}$ or ambient temperature. Crushed mineral particles can provide information that is more representative of the bulk, and in the few cases such specimens were characterised, the fine particles were pressed into a freshly exposed surface of indium. Specimens of n-octanohydroxamic acid were prepared in a similar way. 
XPS data were obtained on an ESCALAB 250Xi spectrometer using monochromatised $\mathrm{Al} \mathrm{K}_{\alpha} \mathrm{X}$-rays focused to a spot size of $0.5 \mathrm{~mm}$ and an electron analyser pass energy of $20 \mathrm{eV}$ for narrow range scans. Included in the binding energies employed for calibration, were $83.96 \mathrm{eV}$ for $\mathrm{Au} 4 f_{7 / 2}$ of metallic gold and $932.6 \mathrm{eV}$ for $\mathrm{Cu} 2 p_{3 / 2}$ of $\mathrm{Cu}$ metal. The pressure in the analysis chamber was better than $5 \times 10^{-9}$ mbar during spectral acquisition. Apart from low collector coverage on $\mathrm{Cu}$, because of the poor electrical conductivity of the minerals or materials investigated, photoelectron spectra had to be obtained while the specimen was under the influence of a low energy electron beam $(4 \mathrm{~V}, 175 \mu \mathrm{A})$ from an in-lens chargeneutralisation flood gun. The observed binding energies, which were lower than the correct values because of over-compensation of charging to achieve minimum linewidth, were referenced to $285.0 \mathrm{eV}$ for the hydrocarbon C $1 s$ photoelectrons. The possibility of beam damage by the low energy electrons was monitored, and in order to minimise any damage, spectra were obtained as quickly as possible at the expense of signal-to-noise. The data were collected and processed under Thermo Scientific Avantage 4.58 and 4.54 software.

\section{Results and discussion}

Characterisation of hydroxamate interaction with oxide copper surfaces is an important aspect of the study of the flotation of copper oxide ores. Spectroscopic techniques are able to observe the interaction of collectors with a mineral surface, both in situ and ex situ, identifying compound formation, chemisorption, bonding and layering. The sensitivity of the techniques varies from the bulk compound formation required for normal Raman spectroscopy through to the ability to characterise sub-monolayers using XPS.

\subsection{Chrysocolla characterisation}

The characterisation of malachite, azurite and pseudomalachite specimens has been reported (Hope et al., 2010a; Parker et al., 2012a). We have previously reported XPS data for the interaction of hydroxamate with chrysocolla (Parker et al., 2012a), however, the mineral specimen investigated contained significant concentrations of $\mathrm{Ca}$ and $\mathrm{Mg}$, and consequently it was not possible to obtain definitive information on the composition and distribution of the adsorbed multilayer. More recently, an essentially pure sample of 
chrysocolla from Clifton (Arizona) was obtained, thereby obviating interferences. We report here our characterisation of the Clifton chrysocolla. Chrysocolla specimens have not been extensively characterised by vibrational spectroscopy and XPS. In particular, there has been confusion concerning the structure and properties of chrysocolla. In the RRUFF database (2011), developed by Downs (2006), the two entries for chrysocolla both exhibit silicate vibrations in the region below $700 \mathrm{~cm}^{-1}$ and an $\mathrm{O}-\mathrm{H}$ stretch at $3613 \mathrm{~cm}^{-1}$. The RRUFF samples did not exhibit significant X-ray diffraction peaks, a result consistent with a noncrystalline sample. Raman and FT-IR spectra of the Clifton chrysocolla are presented in Fig. 1.

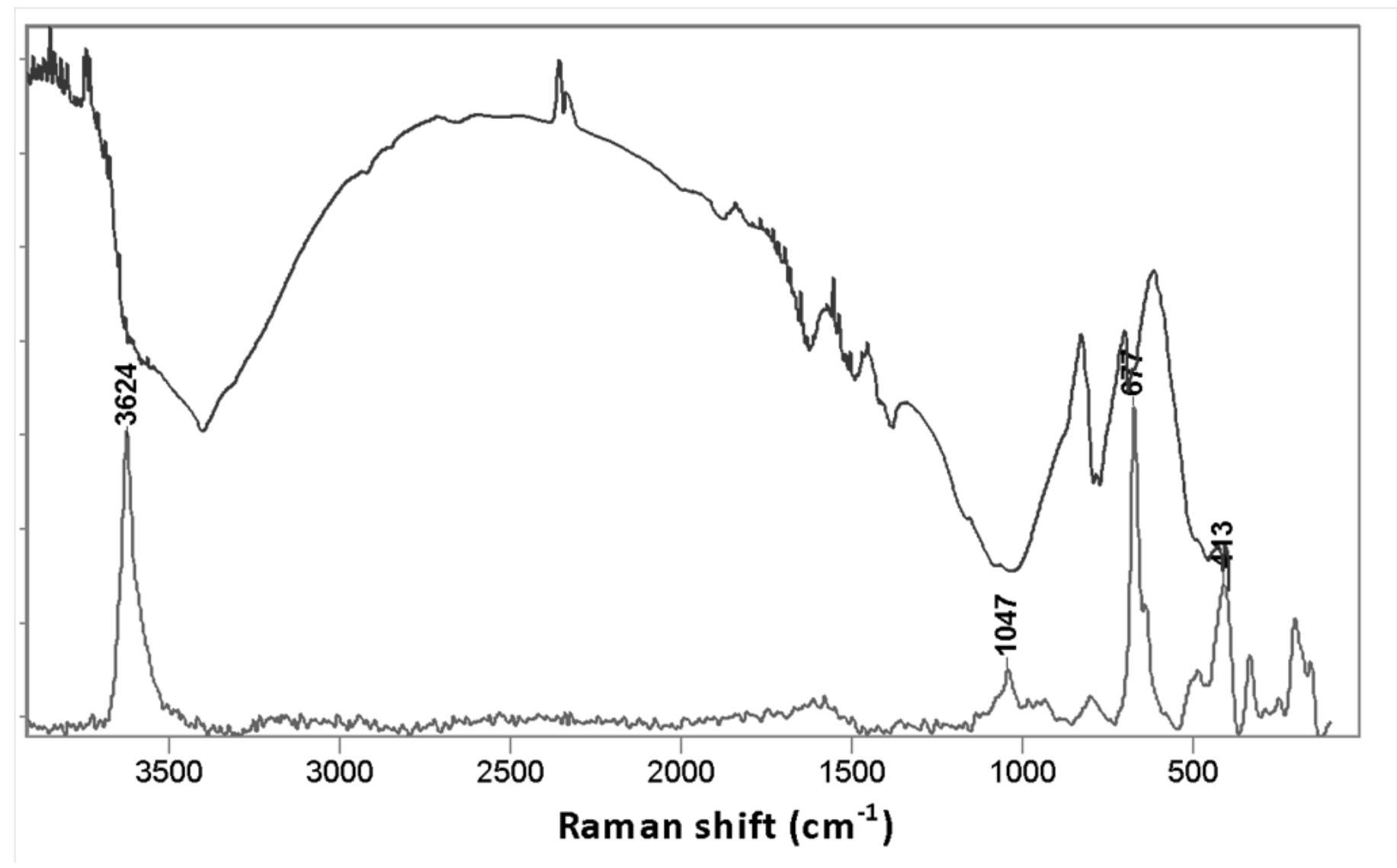

Fig. 1. Raman and FT-IR (top) spectra for chrysocolla

The Raman spectrum obtained is consistent with those reported in the RRUFF database, with the exception of the absence of the $2850 \mathrm{~cm}^{-1}$ hydrocarbon (contamination) bands evident in the RRUFF sample R050053 broad scan. The FT-IR O-H stretching vibration is a broad composite peak characteristic of a water-like $\mathrm{O}-\mathrm{H}$ at $3400 \mathrm{~cm}^{-1}$ and an $\mathrm{O}-\mathrm{H}$ shoulder, attributed to the chrysocolla hydroxide group, near 3600 $\mathrm{cm}^{-1}$. The water $\mathrm{O}-\mathrm{H}$ is not evident in the Raman spectrum, as water is not a good Raman scatterer, and the $3622 \mathrm{~cm}^{-1}$ Raman band observed is assigned to the $\mathrm{O}-\mathrm{H}$ stretch of chrysocolla. This $\mathrm{O}-\mathrm{H}$ stretch is observed 
in both FT-IR and Raman spectra, and occurs at higher wavenumbers than that where water and most free metal hydroxides are found. In Fig. 2, the O-H stretch bands for malachite, chrysocolla and cupric hydroxide are presented. It can be seen that the malachite $\mathrm{O}-\mathrm{H}$ stretch is in the same wavenumber region as cupric hydroxide, whereas for chrysocolla, the band is shifted $250 \mathrm{~cm}^{-1}$ higher, similar to those reported by van der Grift et al. (1989) in their studies of copper-silica catalysts. McKeown (1994) reported XAFS spectra, supporting four oxygen nearest neighbours for the copper atoms in an amorphous matrix. Farges et al. (2007), reported XAFS and $\mu$ XAFS spectra that indicate that the copper structural arrangement in chrysocolla is similar to that observed for spertiniite, $\mathrm{Cu}(\mathrm{OH})_{2}$. They described chrysocolla to be a mesoscopic assemblage composed dominantly of spertiniite, water and amorphous silica. XAFS spectroscopy provides localised rather than bulk chemical and structural information. Chrysocolla could be described as consisting of copper bound to hydroxide units within the amorphous matrix of partially hydrated silica. It does not contain discrete copper hydroxide units or we would observe a similar Raman O-H stretching energy and pattern to that of copper hydroxide for chrysocolla samples.

Scanning electron micrographs of the chrysocolla specimen are presented in Fig. 3. The micrographs show that the chrysocolla consisted of micron sized particles. While Fig. 3(A) presents a smooth ground sample, it can be seen to be formed as a relatively open structure having extensive fissures and holes. The porous mineral nature would enable easy ingress to flotation reagents. This texture is apparent in the (unpolished section) fracture surface imaged as Fig. 3(B). Raghaven and Fuerstenau (1977) used gas adsorption techniques to determine the microporous properties of the mineral. They found that the majority of pores were less than $1.5 \mathrm{~nm}$. Prosser et al. (1965) concluded from water vapour adsorption/desorption isotherms that the chrysocolla pore size was in the range of 1.8 to $20 \mathrm{~nm}$ and that $40 \%$ of the particle volume was occupied by pores. Pores of this size $(<0.02 \mu \mathrm{m})$ range are not discernible at the resolution of our SEM investigations. 




Fig. 2. Raman spectra from the $\mathrm{O}-\mathrm{H}$ stretch region of chrysocolla, malachite and $\mathrm{Cu}(\mathrm{OH})_{2}$.

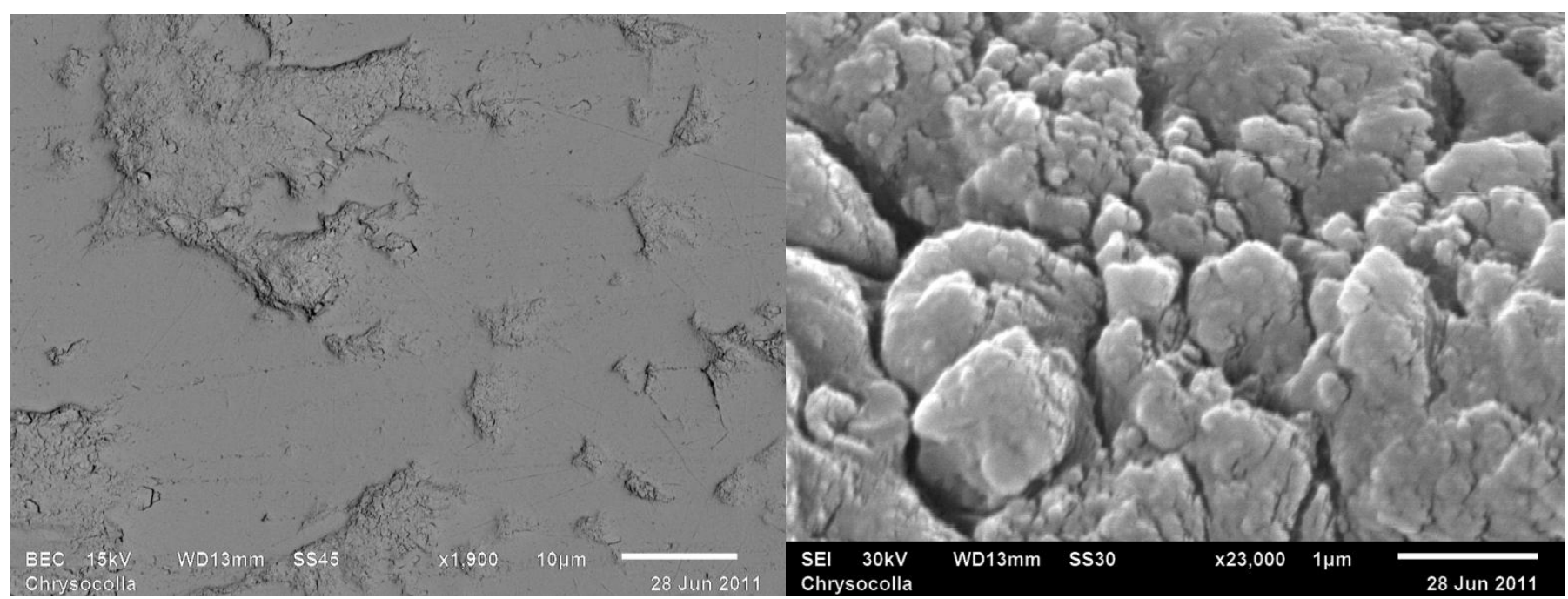

Fig. 3. Images of chrysocolla surface at two magnifications, A - backscatter, B - secondary SEM. 
Investigation of the composition of a polished chrysocolla surface using energy dispersive X-ray (EDX) measurements revealed that the major elements present in the sample were $\mathrm{Si}, \mathrm{Cu}, \mathrm{O}, \mathrm{Al}$, with minor amounts of discrete Fe. EDX maps of the ground chrysocolla surface (Fig. 4), demonstrated that other than $\mathrm{Fe}$, these elements were well dispersed through the sample matrix. Discrete particles of iron present in the sample were, at least partly, in the form of magnetite. A sample of chrysocolla from Mt Isa that we have reported previously (Parker et al., 2012a) contained significant calcium and magnesium impurities, in contrast to this sample.

Powder X-ray diffraction measurements revealed the presence of malachite and quartz in the sample. The iron mineral(s) were not identified by XRD as the concentration was very low. XRF analysis of a powdered sample of chrysocolla for metals, gave $\mathrm{Cu} 24.37 \%$, $\mathrm{Fe} 0.78 \%$ with $\mathrm{Mo}, \mathrm{Nb}, \mathrm{Bi}, \mathrm{Pb}$ and $\mathrm{Zn}$ reported at less than $0.1 \%$.

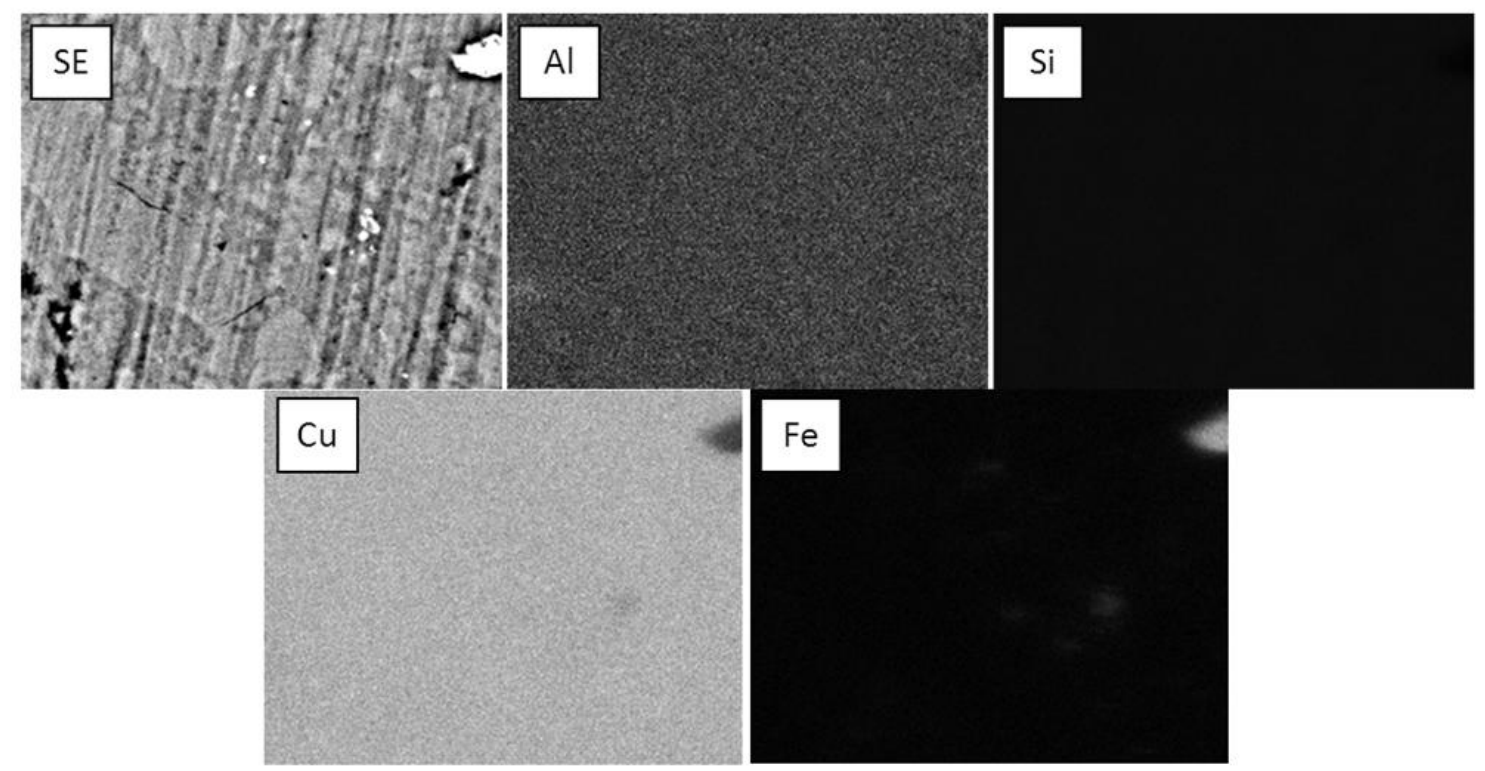

Fig. 4. EDX elemental maps for the identified elements obtained for the region shown in the SE image (analysis area width $190 \mu \mathrm{m}$; black areas on the maps indicate where the element is not detected).

The photoelectron spectra determined at ambient temperature from unconditioned abraded surfaces of selected specimens of the Clifton chrysocolla were consistent with a composition of $\mathrm{Cu}_{2-\mathrm{x}} \mathrm{Al}_{\mathrm{x}}(\mathrm{OH})_{4} \mathrm{H}_{2-\mathrm{x}} \mathrm{Si}_{2} \mathrm{O}_{5} \cdot \mathrm{nH}_{2} \mathrm{O}$ with $\mathrm{x} \approx 0.13$. No iron was evident in the photoelectron spectra from these selected specimens. The Al content was estimated by fitting the $\mathrm{Al} 2 s$ peak (near $121 \mathrm{eV}$ ) on the low 
binding energy edge of the more intense and more complex $\mathrm{Cu} 3 s$ spectrum (principal peak at $\sim 125 \mathrm{eV}$ ), as the interference between the $\mathrm{Al} 2 p$ spectrum $(\sim 75 \mathrm{eV})$ and the more intense principal $\mathrm{Cu} 3 p$ peak $(\sim 78.5 \mathrm{eV})$ was even greater. The only extraneous elements detected were $\sim 5$ at $\% \mathrm{C}$, most of which would have been from the ubiquitous surface carbonaceous contamination with no more than 0.2 at $\%$ as carbonate, and $<1$ at $\%$ of $\mathrm{Cl}$. At ambient temperature, the chrysocolla specimens lost water to the ultra high vacuum of the spectrometer before the pressure was low enough to allow analysis by XPS. Typically, there were two principal $2 p_{3 / 2}$ components in the $\mathrm{Cu} 2 p$ spectrum; a relatively narrow $(\sim 2 \mathrm{eV})$ one at $\sim 933 \mathrm{eV}$ accounting for half of the total $2 p_{3 / 2}$ intensity and a slightly broader one at $\sim 935.2 \mathrm{eV}$ accounting for about $40 \%$. The lower binding energy is indicative of $\mathrm{Cu}^{\mathrm{I}}$ and the higher value is typical of $\mathrm{Cu}^{\mathrm{II}}$ with $\mathrm{O}$ atoms as nearest neighbours. The $\mathrm{Cu}^{\mathrm{II}}$ final state satellite intensity would have been much too low if the component near 933 $\mathrm{eV}$ was also from a $\mathrm{Cu}^{\mathrm{II}}$ species such as $\mathrm{CuO}$, supporting the assignment of that component to $\mathrm{Cu}^{\mathrm{I}}$. The presence of the $\mathrm{Cu}^{\mathrm{I}}$ component suggested that some photo and/or electron reduction of $\mathrm{Cu}^{\mathrm{II}} \rightarrow \mathrm{Cu}^{\mathrm{I}}$ had taken place, possibly facilitated by the loss of water from the mineral, as similar behaviour had not been observed with malachite or pseudomalachite. Losev et al. (1989) had concluded that the electron reduction of surface $\mathrm{Cu}^{\mathrm{II}}$ in $\mathrm{CuO}$ to $\mathrm{Cu}^{\mathrm{I}}$ depended on the presence of adventitious $\mathrm{C}$, but the surface contamination of the chrysocolla was no different from that for the other oxide $\mathrm{Cu}$ minerals studied in the present investigation. The less surface sensitive $\mathrm{Cu} 3 s$ and $3 p$ spectra also reflected the presence of a $\mathrm{Cu}^{\mathrm{I}}$ component, although it was not as obvious as in the $\mathrm{Cu} 2 p$ spectrum because of the greater linewidths and spectral complexity. The X-ray excited $\mathrm{Cu} \mathrm{L}_{3} \mathrm{M}_{4,5} \mathrm{M}_{4,5}$ Auger peak was broad and centred at a kinetic energy of $915.2 \mathrm{eV}$, which was within the $915.5 \pm 0.5 \mathrm{eV}$ range expected for a $\mathrm{Cu}$ oxide mineral. There was no evidence for a component at $918.45 \mathrm{eV}$ from any $\mathrm{Cu}^{0}$ present, but there could have been an unresolved component near $916.2 \mathrm{eV}$ from $\mathrm{Cu}^{\mathrm{I}} / \mathrm{O}$. The $\mathrm{Si} 2 p_{3 / 2}$ binding energy of $103.5 \mathrm{eV}$ was consistent with hydrated silica.

In the $\mathrm{Cu} 2 p$ spectrum (Fig. 5a) from a powdered sample of the same mineral, which outgassed much less than a single piece and hence could be transferred to the analysis chamber much more quickly, the $\sim 933 \mathrm{eV}$ component accounted for less than $10 \%$ of the $2 p_{3 / 2}$ intensity. This observation supported the view that the formation of $\mathrm{Cu}^{\mathrm{I}}$ had been facilitated by the loss of water; i.e., that reduction of $\mathrm{Cu}^{\mathrm{II}} \rightarrow \mathrm{Cu}^{\mathrm{I}}$ by the secondary 
and flood gun electrons had occurred much more readily in the dehydrated surface layers of the mineral. As expected, the $\mathrm{Cu}^{\mathrm{II}} 2 p$ satellites were more intense when the $\mathrm{Cu}^{\mathrm{I}}$ concentration was lower, consistent with the assignment of the low binding energy component to $\mathrm{Cu}^{\mathrm{I}}$ oxide rather than $\mathrm{CuO}$. It can be seen from Fig. 5 that the final state satellite structure for chrysocolla is noticeably different from that for cupric hydroxamate.

XPS data for a powdered Brazilian chrysocolla have been reported by Mosser et al. (1992), but the 4.2 $\mathrm{eV} \mathrm{Cu} 2 p_{3 / 2}$ linewidth would have been too large to enable resolution of a minor component at $\sim 932.8 \mathrm{eV}$. Their $\mathrm{Cu} 2 p_{3 / 2}, \mathrm{O} 1 s$ and $\mathrm{Si} 2 p$ binding energies were reported as 935.8, 532.3 and $102.8 \mathrm{eV}$, respectively.

An abraded surface of the Clifton chrysocolla was cooled to below $150 \mathrm{~K}$ soon after evacuation to minimise loss of water to the vacuum. The $\mathrm{Cu} 2 p$ spectrum contained a component at $\sim 933 \mathrm{eV}$ accounting for $13 \%$ of the $2 p_{3 / 2}$ intensity in addition to the principal component at $935.3 \mathrm{eV}$ and higher binding energy satellites. The low binding energy component was slightly more intense than expected given that water loss from the surface should have been minimal. Nevertheless, it is believed that the origin of the component is surface reduction of $\mathrm{Cu}^{\mathrm{II}}$ to $\mathrm{Cu}^{\mathrm{I}}$ by the secondary and flood gun electrons, rather than a $\mathrm{Cu}^{\mathrm{I}} / \mathrm{O}$ species in the mineral.
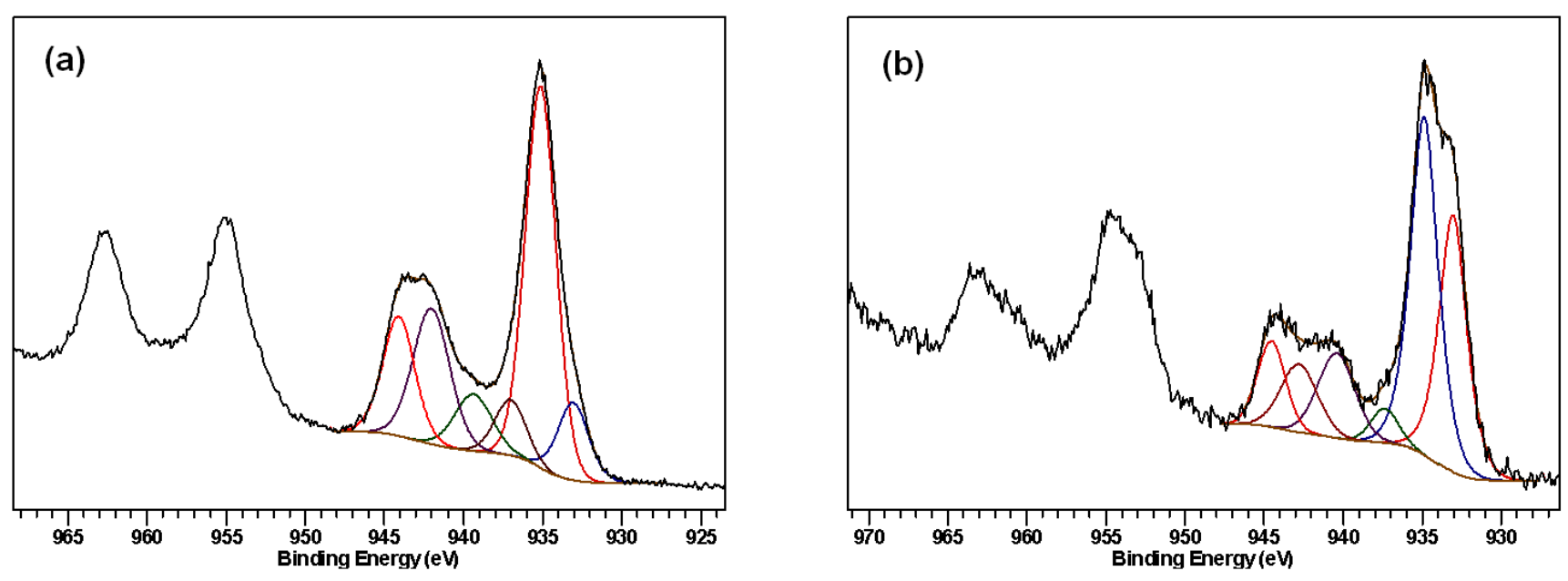

Fig. 5. Cu $2 p$ spectrum from chrysocolla: (a) unconditioned powder obtained as soon as possible after evacuation; (b) abraded surface conditioned in hydroxamate solution for $5 \mathrm{~min}$.

Some of the variance in chrysocolla flotation results reported in the literature might be due to sample composition and characterisation: chrysocolla is amorphous and, therefore, is not able to be characterised by 
$\mathrm{XRD}$, a technique used in many of the literature studies. Our XPS characterisation of samples from Clifton, Arizona, and Mt Isa, Australia (Parker et al., 2012a), have shown that the purity of chrysocolla can vary markedly: impurities, such as $\mathrm{Ca}$ and $\mathrm{Mg}$ in the Mt Isa sample, could significantly affect reagent demand and flotation behaviour. The hydroxyls in the chrysocolla structure are distinct from simple metal hydroxyls in cupric hydroxide or malachite and do not appear to be significantly removed from the structure when the mineral copper reacts with hydroxamate collector.

\subsection{Copper metal studies}

$\mathrm{Cu}$ metal surfaces that had been freshly abraded in air then conditioned in n-octanohydroxamate solution and subsequently rinsed with water were clearly hydrophobic, even after a conditioning time of only 1 min. Photoelectron spectra for conditioning periods of 1-5 min revealed low concentrations of adsorbed hydroxamate and $\mathrm{Cu}^{\mathrm{II}}$ species consistent with at least a fraction of a nominal monolayer (or dispersed multilayer patches) of cupric hydroxamate at the surface. The $\mathrm{Cu} \mathrm{L}_{3} \mathrm{M}_{4,5} \mathrm{M}_{4,5}$ spectra confirmed that $\mathrm{Cu}$ metal remained the predominant $\mathrm{Cu}$ species within the depth analysed by those $\sim 918 \mathrm{eV}$ Auger electrons, and that $\mathrm{Cu}^{\mathrm{I}}$ oxide was also present. Thus, the spectra showed clearly that the native oxide layer was not removed by the hydroxamate.

As observed previously for a $\mathrm{Cu}$ metal surface conditioned in hydroxamate solution for only a few minutes, the total $\mathrm{Cu}^{\mathrm{II}}$ contribution in the $\mathrm{Cu} 2 p$ spectrum, including final state satellites, accounted for less than $30 \%$ of the $2 p_{3 / 2}$ peak intensity, and the $\mathrm{Cu}^{\mathrm{II}}: \mathrm{N}$ atomic ratio was $\sim 0.6$. Although most of the $\mathrm{Cu}^{\mathrm{II}}$ at the surface would have been associated with hydroxamate, a $\mathrm{Cu}^{\mathrm{II}}: \mathrm{N}$ atomic ratio significantly lower than 1.0 indicated that $\mathrm{Cu}^{\mathrm{II}}$ (hydroxamate) could not have been the only hydroxamate species at the surface. The possibility that the low $\mathrm{Cu}^{\mathrm{II}}: \mathrm{N}$ value might have arisen because of the formation of $\mathrm{Cu}$ (hydroxamate $)_{2}$ at the solid/collector interface had previously been eliminated on the grounds that the composition of the multilayer when 'thick' (comprising at least 3 molecular layers) was similar to that of the bulk complex.

Establishing unequivocally the composition of the cupric hydroxamate when it consists of at most two molecular layers is not straightforward. Meaningful fitting of the $\mathrm{Cu} 2 p$ spectrum requires valid representations of the background under the $2 p_{3 / 2}$ principal peaks and $\mathrm{Cu}^{\mathrm{II}}$ final state satellites, and of the 
asymmetric lineshape for the $2 p_{3 / 2}$ peak from the $\mathrm{Cu}$ metal substrate. When the $\mathrm{Cu}$ (II concentration at the surface is low, any deficiency in these two shapes will have a disproportionate impact on the $\mathrm{Cu}^{\mathrm{II}} 2 p$ component deduced. An alternative approach is to subtract the $\mathrm{Cu} 2 p$ spectrum for $\mathrm{Cu}$ metal exposed briefly to air from the corresponding spectrum for $\mathrm{Cu}$ metal conditioned in hydroxamate for a short period following brief exposure to air. However, the subtraction of photoelectron spectra containing relatively narrow peaks is difficult, as artefacts are produced in the difference spectrum unless intensity normalisation and energy calibration are correct, and the substrate is exactly the same for both spectra. It is especially difficult when spectra have been determined as rapidly as possible at the expense of signal-to-noise to minimise any beam damage; under those conditions, the difference spectrum will appear quite noisy. Nevertheless, the approach should provide the information sought.

The difference $\mathrm{Cu} 2 p$ spectrum for an abraded $\mathrm{Cu}$ metal surface conditioned in hydroxamate solution for 2 min is shown in Fig. 6. The difference spectrum displays a 'negative spike' near $932.6 \mathrm{eV}$ almost certainly because of slightly different substrate $\mathrm{Cu}^{0}$ and $\mathrm{Cu}^{\mathrm{I}}$ contributions in the normalised $\mathrm{Cu} 2 p_{3 / 2}$ peaks prior to subtraction. As expected the difference spectrum is also quite noisy, however, the spectral characteristics including final state satellites are essentially indistinguishable from those for bulk cupric hydroxamate (Hope et al., 2011). The binding energy of the principal $2 p_{3 / 2}$ peak, $935.15 \mathrm{eV}$, should be an accurate value for the cupric hydroxamate given the proximity to the $\mathrm{Cu}$ metal reference peak at $932.6 \mathrm{eV}$ and given the low coverage on a substrate of adequate electrical conductivity. Note that in fitting this difference spectrum, a linear background is appropriate because there is essentially no sub-surface contribution to the spectrum. 




Fig. 6. $\mathrm{Cu} 2 p$ spectrum of the difference between the spectrum for $\mathrm{Cu}$ metal exposed briefly to air and that for $\mathrm{Cu}$ metal conditioned in hydroxamate solution for $2 \mathrm{~min}$.

Confirmation of the multilayer as $\mathrm{Cu}$ (hydroxamate) rather than $\mathrm{Cu}$ (hydroxamate) ${ }_{2}$ at low coverage was completed by the form of the $\mathrm{N} 1 s$ spectrum from the conditioned surface. At least $85 \%$ of the $\mathrm{N} 1 s$ intensity was at a binding energy of $400.0 \mathrm{eV}$, with the remaining $15 \%$ near $401.2 \mathrm{eV}$. The high binding energy component can be assigned to hydroxamate $\mathrm{N}$ atoms that would have been protonated, rather than deprotonated and interacting with a $\mathrm{Cu}$ atom in an adjacent cupric hydroxamate molecule or in the oxide substrate. If the hydroxamate near the $\mathrm{Cu}$ /collector interface had been $\mathrm{Cu}$ (hydroxamate) $)_{2}$, then the $\mathrm{N}$ in that multilayer would have been protonated, in which case most of the $\mathrm{N} 1 s$ intensity would have been near 401 $\mathrm{eV}$ rather than $400 \mathrm{eV}$. Thus it can be concluded that regardless of the thickness of the cupric hydroxamate multilayer, its composition must have been $\mathrm{Cu}($ hydroxamate).

Notwithstanding the above conclusion, the fact remains that up to $15 \%$ of $\mathrm{N}$ atoms were protonated. Possible reasons for that degree of protonation include $\mathrm{N}$ in hydroxamate ligands at the extremities of multilayer patches of oligomeric cupric hydroxamate, and $\mathrm{N}$ in co-adsorbed hydroxamic acid. To date, the first reason has been considered the more likely, as a low intensity component at $\sim 401 \mathrm{eV}$ was also observed in the $\mathrm{N} 1 s$ spectrum from bulk cupric hydroxamate (Hope et al., 2011), and it had been expected that any hydroxamic acid adsorbed while still in the collector solution would be removed when the surface was rinsed with water prior to characterisation by XPS. This assessment was despite the fact that Fuerstenau and Pradip (1984) had proposed co-adsorbed hydroxamate and hydroxamic acid as being responsible for floatability at $\mathrm{pH} \sim 9$. However, the $\mathrm{N}$ atoms giving rise to the $401 \mathrm{eV} \mathrm{N} 1 s$ component have been found to 
be quite susceptible to deprotonation by low energy electrons from a flood-gun, suggesting that at least some hydroxamic acid might also be adsorbed. Accordingly, it became clear that it was necessary to obtain high resolution photoelectron spectra from n-octanohydroxamic acid.

\subsection{Solid n-octanohydroxamic acid studies}

The C $1 s$ spectrum for recrystallised n-octanohydroxamic acid consisted of a hydrocarbon peak at an assigned binding energy of $285.0 \mathrm{eV}$ accounting for close to $75 \%$ of the $\mathrm{C} 1 \mathrm{~s}$ intensity, and two components each accounting for close to $12.5 \%$ of the intensity, a fully resolved one at $288.2 \mathrm{eV}$ that would have arisen from $\mathrm{C}$ atoms bonded to $\mathrm{O}$ and $\mathrm{N}$, and an unresolved component fitted at $285.9 \mathrm{eV}$ that would be consistent with $\mathrm{C}$ atoms at the end of the heptyl chains nearer to the $\mathrm{O}$ and $\mathrm{N}$ atoms. The corresponding $\mathrm{N} 1 s$ spectrum was predominantly a single peak at $401.05 \mathrm{eV}$, but minor components at 399.2 and $403.3 \mathrm{eV}$ accounting for $3 \%$ and $4 \%$ of the intensity, respectively, were required for an adequate fit. These minor components could either be artefacts arising from non-uniform charge compensation, or have arisen from degradation products formed under the X-ray and low energy electron beams. The O $1 s$ spectrum consisted of two peaks of approximately equal intensity; a relatively narrow $(1.4 \mathrm{eV})$ one at $531.5 \mathrm{eV}$ and a broader $(1.9 \mathrm{eV})$ component at $533.4 \mathrm{eV}$. A binding energy of $533.4 \mathrm{eV}$ is similar to that for physically adsorbed water, but the concentration of $\mathrm{O}$ based on the total $\mathrm{O} 1 s$ intensity was double that of $\mathrm{N}$ based on the $\mathrm{N} 1 s$ intensity, as expected, consequently in this case the component at $533.4 \mathrm{eV}$ appears to correspond to $\mathrm{O}$ in the $\mathrm{OH}$ bonded to $\mathrm{N}$. The $\mathrm{O} 1 s$ binding energies observed for n-octanohydroxamic acid are in broad agreement with the values of 531.8 and $533.8 \mathrm{eV}$ obtained by Lindberg et al. (1978) for bulk benzohydroxamic acid. A binding energy of $531.5 \mathrm{eV}$ is close to the value of $531.4 \mathrm{eV}$ observed for carbonyl $\mathrm{O}$ in polyamides (Solomun et al., 2004).

In light of the XPS data for hydroxamic acid, it would be expected that an $\mathrm{O} 1 s$ component near $533.4 \mathrm{eV}$ of intensity comparable with that of the $401 \mathrm{eV} \mathrm{N} 1 s$ component would be observed if hydroxamic acid had been co-adsorbed at a conditioned surface. An O $1 s$ component at this binding energy was usually observed for $\mathrm{Cu}$ surfaces conditioned in hydroxamate, but it had been assigned to physically adsorbed water. Although all surfaces were hydrophobic, some physically adsorbed water was considered possible when the 
coverage was low and probably dispersed in patches. Physically adsorbed water would be less likely at high collector coverage, nevertheless while the spectroscopic evidence remains consistent with some co-adsorbed hydroxamic acid, it does not provide definitive evidence for its presence.

\subsection{Oxide $C u^{I I}$ mineral conditioning studies}

For $\mathrm{Cu}^{\mathrm{II}}$ minerals, interaction with hydroxamate would be somewhat different, in that the hydroxamate would exchange with hydroxyl groups bound to $\mathrm{Cu}^{\mathrm{II}}$ atoms in the mineral surface. Typically, this process does not stop at a compact, well-formed monolayer, but rather multilayers and islands of cupric hydroxamate are formed. The existence of this bulk product enables observation using normal Raman spectroscopy and Raman spectra of adsorbed multilayers have been reported previously for malachite and azurite (Hope et al., 2010a).

For Raman spectroscopy to be utilised to identify the formation of multilayer $\mathrm{Cu}$ n-octanohydroxamate on oxide copper minerals, it was necessary to condition the minerals for relatively long time-frames, compared to flotation conditions, in order to obtain a thick enough product layer to be detectable. In Fig. 7 the Raman spectra for chrysocolla, malachite, azurite and pseudomalachite that have been treated with 0.1 $\mathrm{mM}$ potassium hydrogen n-octanohydroxamate at $\mathrm{pH} 11$ for 60 minutes are presented. 


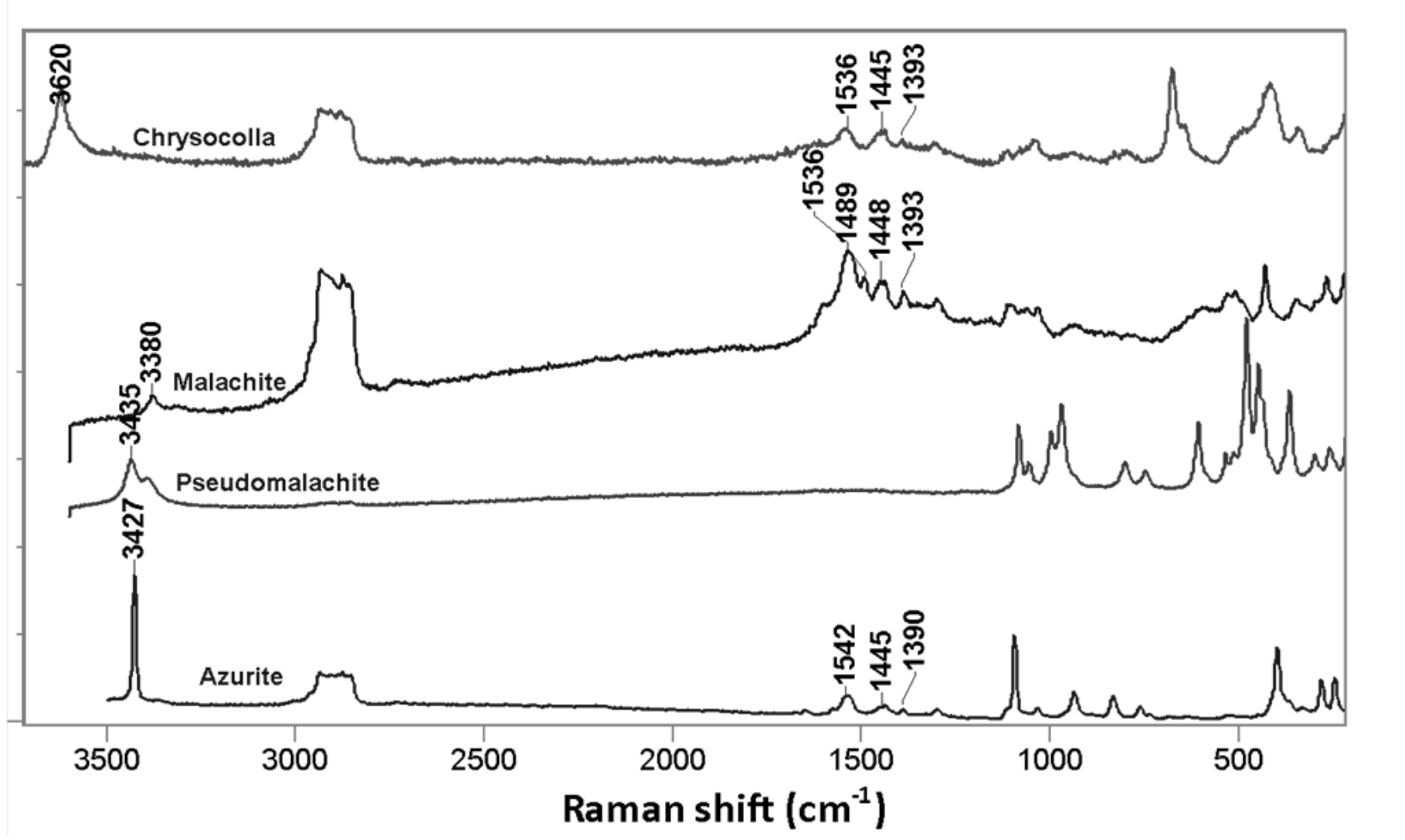

Fig. 7. Raman spectra obtained from minerals exposed to potassium hydrogen $n$-octanohydroxamate solution $\left(10^{-4}\right.$ M, pH 11, 60 min): A; chrysocolla, B; malachite, C; pseudomalachite, D; azurite.

Malachite, azurite and chrysocolla form substantial copper n-octanohydroxamate product layers that are easily observed in the Raman spectrum. In contrast, pseudomalachite exhibits a very weak intensity hydrocarbon $\mathrm{C}-\mathrm{H}$ stretch similar in shape to that observed for n-octanohydroxamate, but it is not possible to unequivocally assign characteristic bands for a copper hydroxamate product layer in the Raman spectrum. In all spectra presented in Fig. 7 we can observe the bands that are emitted by the (underlying) mineral. Malachite has the greatest copper hydroxamate to mineral band ratio, characteristic of highest copper hydroxamate formation for the collector treatment conditions used.

In Fig. 8 we present the FT-IR and Raman spectra for the hydroxamate treated Clifton chrysocolla sample. 


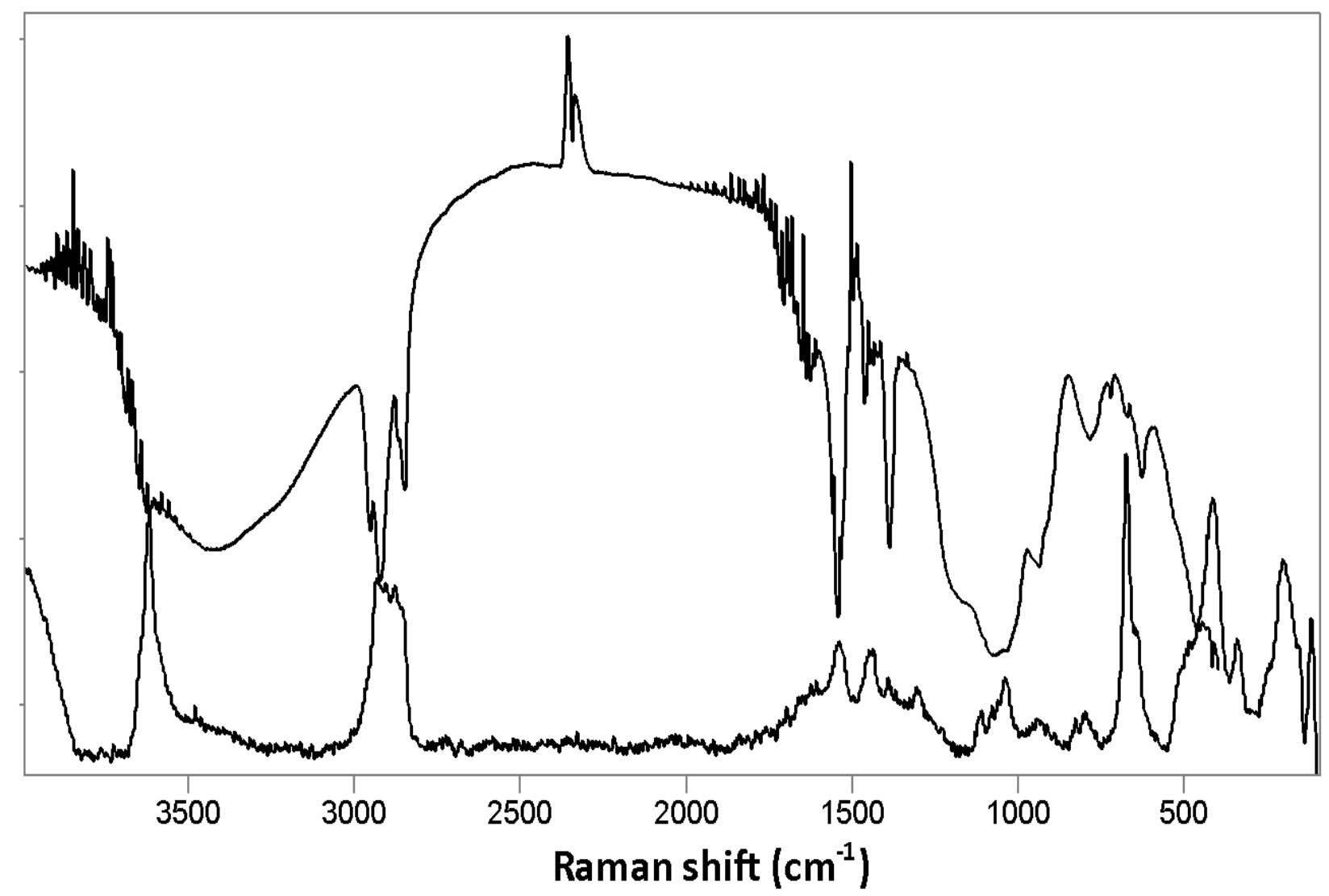

Fig. 8. Raman and FT-IR (top) spectra from chrysocolla exposed to $10^{-3} \mathrm{M}$ potassium hydrogen n-octanohydroxamate solution, $\mathrm{pH} 11,10$ min.

Comparing the spectra presented in Fig. 1 with these spectra we can observe that the treated sample exhibits the characteristic bands (particularly the $1550 \mathrm{~cm}^{-1} \mathrm{C}=\mathrm{N}$ band and the alkyl $\mathrm{C}-\mathrm{H}$ at $2900 \mathrm{~cm}^{-1}$ ) associated with the formation of copper n-octanohydroxamate. We can also observe that the Raman and FTIR stretching vibrations for the hydroxide component of the chrysocolla are unchanged following exposure to the hydroxamate. The $3600 \mathrm{~cm}^{-1}$ hydroxide vibrations are associated with the copper in the chrysocolla but it is apparent that the hydroxamate is not replacing the copper hydroxide groups responsible for generating the observed chrysocolla $\mathrm{O}-\mathrm{H}$ stretch. This could indicate that we are observing an $\mathrm{OH}$ stretching vibration associated with silica, or that the $\mathrm{OH}$ associated with the copper inside the chrysocolla is not accessible to the flotation reagent. This hydroxyl was not substantially exchangeable with $\mathrm{D}_{2} \mathrm{O}$. The chrysocolla specimen was porous, and when exposed to isomet hydrocarbon cutting fluid during sample preparation for another study, it irreversibly absorbed the hydrocarbons, and the hydrocarbon was retained even after soaking and sonicating in dichloromethane. 
The concentration of $\mathrm{Cu}$ (hydroxamate) on conditioned surfaces of $\mathrm{Cu}$ metal can be estimated from the photoelectron spectra because the $\mathrm{Cu}^{0}$ and $\mathrm{Cu}^{\mathrm{I}}$ in the substrate can be differentiated spectroscopically from the $\mathrm{Cu}^{\mathrm{II}}$ in multilayer cupric hydroxamate. Such relatively straightforward differentiation is also possible for cuprite and the $\mathrm{Cu}$ sulfides, but it is not available for the $\mathrm{Cu}^{\mathrm{II}}$ oxide minerals, as there are only subtle differences between the principal $2 p$ and $3 p$ binding energies for $\mathrm{Cu}^{\mathrm{II}}$ with oxygen nearest neighbours in the minerals and in hydroxamate. The relevant $\mathrm{Cu} \mathrm{L}_{3} \mathrm{M}_{4,5} \mathrm{M}_{4,5}$ kinetic energies are also insufficiently different to be useful in this regard. The final state satellite structure and intensity relative to the principal $\mathrm{Cu} 2 p$ peaks are slightly different for each $\mathrm{Cu}$ oxide mineral and cupric hydroxamate, and while that would allow differentiation of the untreated materials, it would not normally allow a determination of the concentration of cupric hydroxamate adsorbed at the surface of an oxide $\mathrm{Cu}$ mineral. Thus, because the $\mathrm{Cu}$ in an oxide $\mathrm{Cu}^{\mathrm{II}}$ mineral substrate cannot be clearly differentiated from the $\mathrm{Cu}$ in adsorbed $\mathrm{Cu}$ (hydroxamate), it is unlikely that chemisorption of hydroxamate collector to $\mathrm{Cu}$ in a $\mathrm{Cu}^{\mathrm{II}}$ mineral surface, thereby establishing an anchor layer, could be substantiated by XPS alone.

The estimation of the coverage of hydroxamate collector on an oxide $\mathrm{Cu}^{\mathrm{II}}$ mineral is also less straightforward compared with that on a $\mathrm{Cu}$ metal or sulfide mineral substrate. The two values of $\mathrm{Cu}: \mathrm{N}$ based on the $\mathrm{Cu} 2 p$ and $3 p$ intensities continue to provide an estimate of coverage, but those values alone are not always able to distinguish low uniform coverage from thicker patches. To facilitate the estimation of adsorbate coverage on an oxide $\mathrm{Cu}$ substrate, another suitable element or anion that is an integral part of the oxide mineral and that is not directly involved in the collector adsorption is required. This criterion is satisfied by carbonate in malachite, phosphate in pseudomalachite, or Si in chrysocolla. The criterion is not met by the minor 'impurity' elements typically found in the oxide $\mathrm{Cu}$ minerals such as $\mathrm{Ca}$ and $\mathrm{Mg}$, as these elements would be expected to also interact with hydroxamate at high collector concentrations, and some might end up in the adsorbed multilayer. For multilayer coverage of the oxide $\mathrm{Cu}$ minerals by cupric hydroxamate, the surface $\mathrm{N}$ concentration should approach 8.3 at\% (excluding $\mathrm{H}$ ), or $7.5-8$ at\% in practice given that all surfaces exposed to the atmosphere adsorb some extraneous carbonaceous material. For high collector coverage on an oxide $\mathrm{Cu}^{\text {II }}$ mineral containing no minor elements, $\mathrm{Cu}: \mathrm{N}$ should approach, but be not less than, 1.0 unless hydroxamic acid were co-adsorbed with the $\mathrm{Cu}$ (hydroxamate). As noted above, the $\mathrm{N}$ 
$1 s$ binding energy for any co-adsorbed hydroxamic acid would be near $401 \mathrm{eV}$, in which case $\mathrm{Cu}: \mathrm{N}_{\mathrm{d}}$ should not be $<1.0$ (where $\mathrm{N}_{\mathrm{d}}$ is the concentration of $\mathrm{N}$ that is deprotonated but interacting with $\mathrm{Cu}$ atoms and has an $\mathrm{N} 1 s$ binding energy of $400 \mathrm{eV}$ ). Even hydroxamate chemisorbed to $\mathrm{Cu}$ atoms in the mineral surface should not lower this ratio, and for low coverage, $\mathrm{Cu}: \mathrm{N}$ should be $>1.0$ as some $\mathrm{Cu}$ in the mineral substrate should remain within the depth analysed even by $\mathrm{Cu} 2 p$ photoelectrons, and certainly within the greater depth analysed by $\mathrm{Cu} 3 p$ photoelectrons.

For oxide $\mathrm{Cu}$ minerals containing minor elements that could also interact with hydroxamate, on the other hand, $\mathrm{Cu}: \mathrm{N}$ might be $<1.0$. Whether or not $\mathrm{Cu}: \mathrm{N}_{\mathrm{d}}$ would remain $>1.0$ would depend on the $\mathrm{N} 1 s$ binding energy for the metal hydroxamates concerned. For example, the N $1 s$ binding energy for Ca(hydroxamate) ${ }_{2}$ is $400.65 \mathrm{eV}$, and a component at this binding energy would probably not be resolved from components at 400 and $401 \mathrm{eV}$, thereby making a value for $\mathrm{Cu}: \mathrm{N}_{\mathrm{d}}$ unreliable under those circumstances.

The detection by XPS of hydroxamate multilayers adsorbed on malachite, nominally $\mathrm{CuCO}_{3} \cdot \mathrm{Cu}(\mathrm{OH})_{2}$, has been reported previously (Parker et al. 2012a), but the malachite that had been investigated, like most malachite specimens, contained significant concentrations of $\mathrm{Ca}$ and $\mathrm{Mg}$. More recently, malachite from Morocco that contained significantly lower minor element concentrations was obtained, but surfaces of even that specimen characterised by XPS typically contained 4 at $\% \mathrm{Cu}, 0.4$ at $\% \mathrm{Ca}$ and 0.1 at $\% \mathrm{Mg}$. No residual $\mathrm{K}$ or other minor elements were detected. The $\mathrm{N} 1 s$ spectra from surfaces conditioned in hydroxamate solution were without resolved structure, but appeared to contain a component near $400.7 \mathrm{eV}$ in addition to the principal one at $400.0 \mathrm{eV}$, and a third component near $401 \mathrm{eV}$ accounted for up to $10 \%$ of the total $\mathrm{N} 1 \mathrm{~s}$ intensity. Although the fitting could not have been unique, the significant $\mathrm{N} 1 s$ intensity at $401 \mathrm{eV}$ and comparable $\mathrm{O} 1 s$ intensity near $533 \mathrm{eV}$ strongly suggested some hydroxamic acid had been co-adsorbed, and indeed it was necessary to assume co-adsorption of acid as well as adsorption of $\mathrm{Ca}$ (hydroxamate) ${ }_{2}$ in order to rationalise the measured $\mathrm{Cu}: \mathrm{N}$ values. Assignment of the component near $533 \mathrm{eV}$ to water physically adsorbed at the clearly hydrophobic surface would have been less credible than assignment to co-adsorbed hydroxamic acid. The well-resolved carbonate peak in the C $1 s$ spectrum was at a binding energy of 289.7 
$\mathrm{eV}$, and the intensity of this peak allowed hydroxamate coverage to be estimated. After conditioning times approaching $10 \mathrm{~min}$, the multilayer was sufficiently thick for the carbonate peak to be no longer discernible.

For pseudomalachite, nominally $\mathrm{Cu}_{5}\left(\mathrm{PO}_{4}\right)_{2}(\mathrm{OH})_{4}$, the phosphate $\mathrm{P} 2 s$ and $2 p$ peaks near 192 and $135 \mathrm{eV}$ in the photoelectron spectrum provide an alternative substrate diagnostic marker to the carbonate peak in malachite for the estimation of hydroxamate collector adsorption. The $\mathrm{P} 2 p$ unresolved doublet is more intense and narrower than the P $2 s$ peak, but is complicated by being superimposed on energy loss features of the $\mathrm{Cu} 3 s$ peak. The survey spectrum from unconditioned surfaces of the pseudomalachite specimen investigated revealed a very low concentration of $\mathrm{Ca}$ as the only significant impurity. In particular, peaks from neither $\mathrm{Al}$ nor $\mathrm{Mg}$ were evident. The $\mathrm{Cu} 2 p$ spectrum incorporated final state satellites that were more intense relative to the principal $2 p$ peaks than for cupric n-octanohydroxamate. The $\mathrm{O} 1 s$ spectrum could be fitted with a principal component of width $1.7 \mathrm{eV}$ at $531.35 \mathrm{eV}$ that can be assigned to oxygen in the mineral lattice and a minor component near $533 \mathrm{eV}$ attributable to adsorbed water. The $\mathrm{P} 2 p$ intensity was greater than that of the $\mathrm{Cu} 3 s$ peak which was at a binding energy $\sim 8.5 \mathrm{eV}$ lower than the $\mathrm{P} 2 p$.

Photoelectron spectra from an abraded pseudomalachite surface conditioned in hydroxamate solution for 1 min included a strong $\mathrm{N} 1 s$ peak and more intense $\mathrm{C} 1 s$ spectrum, as well as $\mathrm{P} 2 s$ and $2 p$ spectra that were markedly less intense, than for the unconditioned mineral. A Ca $2 p$ doublet was barely discernible. The $\mathrm{Cu}$ $2 p$ spectrum now resembled that for cupric hydroxamate more than for the unconditioned substrate, and the $\mathrm{C}, \mathrm{O}$ and $\mathrm{N} 1 s$ spectra were all consistent with the adsorption of multilayer cupric hydroxamate, notwithstanding the short conditioning time. In particular, the $\mathrm{N} 1 s$ spectrum consisted of a component at $400 \mathrm{eV}$ accounting for $84 \%$ of the intensity and an unresolved component at $401.3 \mathrm{eV}$ accounting for the remaining $16 \%$. Based on the total $\mathrm{Cu} 2 p_{3 / 2}$ intensity, $\mathrm{Cu}: \mathrm{N}$ was close to 1.0 and $\mathrm{Cu}: \mathrm{N}_{\mathrm{d}}$ was 1.2 , consistent with a substantial coverage of cupric hydroxamate. However, based on the total intensity of the less surface sensitive $\mathrm{Cu} 3 p$ spectrum, $\mathrm{Cu}: \mathrm{N}$ was 4.7 , indicating that the cupric hydroxamate coverage would have been quite uniform and a few molecular layers thick. This conclusion would be consistent with the similarly less surface sensitive phosphate $\mathrm{P} 2 s$ and $2 p$ peaks remaining evident, with the $\mathrm{P} 2 p$ intensity slightly lower than the $\mathrm{Cu} 3 s$. The $\mathrm{O} 1 s$ spectrum was largely a single peak of width $1.8 \mathrm{eV}$ at $531.7 \mathrm{eV}$ that would have 
contained unresolved components from the adsorbed cupric hydroxamate and from the underlying mineral. The spectrum contained a small component near $533 \mathrm{eV}$ that would be consistent with some hydroxamic acid co-adsorbed at the clearly hydrophobic surface.

The spectra for an abraded pseudomalachite surface conditioned in hydroxamate solution for 5 min were qualitatively similar to those for 1 min conditioning. Any Ca within the depth analysed was below the detection limit. The hydroxamate coverage would have been somewhat thicker for the longer conditioning time, as although $\mathrm{Cu}: \mathrm{N}$ was similarly close to 1.0 based on the total $\mathrm{Cu} 2 p_{3 / 2}$ intensity, it was 1.2 based on the total $\mathrm{Cu} 3 p$ intensity. The $\mathrm{P} 2 s$ and $2 p$ peaks remained discernible, but less so than following the $1 \mathrm{~min}$ conditioning period, and the $\mathrm{P} 2 p$ intensity was now significantly lower than the $\mathrm{Cu} 3 s$. The $\mathrm{O} 1 s$ spectrum comprised a major component of width $1.75 \mathrm{eV}$ at $531.9 \mathrm{eV}$ that would have arisen mostly from the adsorbed cupric hydroxamate, and a minor component of low intensity near $533 \mathrm{eV}$ that could be attributed to some co-adsorbed hydroxamic acid. These observations suggest that, notwithstanding its lower solubility, pseudomalachite should be as floatable as malachite with n-octanohydroxamate collector.

In the photoelectron spectra from abraded surfaces of Clifton chrysocolla conditioned for $5 \mathrm{~min}$ in saturated $\mathrm{KH}(\text { octanohydroxamate })_{2}$ solution at its unadjusted $\mathrm{pH}$ of $\sim 9.5$, and subsequently rinsed with water, no extraneous elements were evident. In particular, no $\mathrm{K}$ was discernible, confirming that any physically adsorbed collector had been rinsed from the surface. The spectra, especially the $\mathrm{Cu} 2 p$ final state satellite structure (Fig. 5b) which now resembled that for cupric hydroxamate more closely than that for unconditioned chrysocolla, showed unequivocally that cupric hydroxamate was adsorbed. The $\mathrm{Cu}$ and $\mathrm{N}$ atomic concentrations at the surface based on the intensities of the $\mathrm{Cu} 2 p$ and $\mathrm{N} 1 s$ peaks were about $4 \%$, but $11 \% \mathrm{Si}$ was also present within the depth analysed. These observations suggest that at least a thin multilayer of cupric hydroxamate had been adsorbed at the surface if the coverage was uniform. It is difficult to estimate the precise coverage as the collector most probably adsorbed in multilayer patches, but the coverage could not have been both thick and uniform because of the relatively high Si concentration; i.e., some of the mineral substrate remained within the $2-4 \mathrm{~nm}$ depth analysed, either under or between patches of the adsorbed cupric hydroxamate. The Cu concentrations based on the less surface sensitive $\mathrm{Cu} 3 s$ and $3 p$ 
intensities were comparable with that based on the more surface sensitive $\mathrm{Cu} 2 p$, consistent with multilayer patches rather than a thinner, more uniform coverage. Although in principle the $\mathrm{Al} 2 p$ and $2 s$ spectra made determination of the $\mathrm{Cu} 3 p$ and $3 s$ intensities difficult, the $\mathrm{Al}$ peaks at conditioned surfaces remained significantly less intense than the $\mathrm{Cu}$, so that the $\mathrm{Cu}$ concentration estimated from the intensities of the $3 p$ and $3 s$ peaks should have been reliable.

As for the untreated mineral, the $\mathrm{Cu} 2 p$ spectrum determined at ambient temperature (Fig. 5b) contained two partly-resolved principal components, in this case with the component at a $2 p_{3 / 2}$ binding energy of $\sim 933$ $\mathrm{eV}$ accounting for $\sim 30 \%$ of the total $2 p_{3 / 2}$ intensity and the component near $935 \mathrm{eV}$ accounting for $\sim 40 \%$. The $\mathrm{Cu}^{\mathrm{II}}$ final state satellite intensity was slightly higher than that observed for bulk cupric hydroxamate. The corresponding N $1 s$ spectrum (Fig. 9), which comprised a relatively narrow (1.5 eV) major component at $400.0 \mathrm{eV}$ accounting for $87 \%$ of the $\mathrm{N} 1 s$ intensity, and a minor component at $401.45 \mathrm{eV}$ accounting for the remaining $13 \%$, was broadly the same as that observed for bulk cupric hydroxamate apart from a slightly more intense minor component. The $\mathrm{C} 1 s$ and $\mathrm{O} 1 s$ spectra were also consistent with multilayer patches of adsorbed hydroxamate.



Fig. 9. N $1 s$ spectrum from an abraded chrysocolla surface conditioned in hydroxamate solution for 5 min.

While the atomic concentrations of $\mathrm{Cu}$ and $\mathrm{N}$ near the surface were comparable, the $\mathrm{N} 1 s$ intensity was slightly higher than expected, and $\mathrm{Cu}: \mathrm{N}_{\mathrm{d}}$ was $\sim 0.95$ rather than 1.0 or higher. The discrepancy is approaching experimental error, but one possible reason for a slightly higher than expected adsorbed 
collector concentration would be interaction of hydroxamate with Al. The acetohydroxamate complexes of $\mathrm{Al}$ and $\mathrm{Cu}$ have a similarly high stability (Anderegg et al., 1963), and the stability of the $\mathrm{Al}$ and $\mathrm{Cu}$ n-octanohydroxamates is expected to be similarly high. The extent of interaction of hydroxamate with Al would depend on where the $\mathrm{Al}$ was located; greater interaction would be expected if the $\mathrm{Al}$ were in sites normally occupied by $\mathrm{Cu}$ than if it were present as an aluminosilicate. It is considered most likely that the Al substitutes for $\mathrm{Cu}$ in chrysocolla (Crane et al., 2001), in which case some $\mathrm{Al}$ (hydroxamate) ${ }_{3}$ might even be present in the adsorbed multilayer, but as noted above neither the $\mathrm{Al} 2 s$ nor $2 p$ intensity appeared to be sufficiently high for a significant concentration to be present.

The $\mathrm{N}$ in any 'excess' hydroxamate would be expected to be protonated, and hence its $\mathrm{N} 1 s$ binding energy would be expected to be higher than the $400.0 \mathrm{eV}$ for hydroxamate adsorbed to $\mathrm{Cu}$ atoms in the mineral surface and for hydroxamate in multilayer $\mathrm{Cu}$ (hydroxamate). Since the fitted component at $\sim 401.5$ $\mathrm{eV}$ accounted for $13 \%$ of the $\mathrm{N} 1 s$ intensity, compared with no more than $5 \%$ for bulk cupric n-octanohydroxamate, it is possible that the additional intensity near $401.5 \mathrm{eV}$ arose from some co-adsorbed hydroxamic acid as well as hydroxamate adsorbed to $\mathrm{Al}$ atoms in the mineral surface. However, the narrow linewidth observed for the $\mathrm{N} 1 s$ spectrum would have precluded a significant concentration of hydroxamate interacting with elements other than $\mathrm{Cu}$.

Herrera-Urbina et al. (2010) have suggested that, in the absence of collector, chrysocolla readily loses $\mathrm{Cu}$ to an aqueous environment and consequently flotation of that mineral should be carried out with limited conditioning after dry comminution. A corollary of that conclusion would be that the different $\mathrm{Cu}$ solubilities of the oxide $\mathrm{Cu}$ minerals should be reflected in the extent of multilayer cupric hydroxamate coverage on the different oxide $\mathrm{Cu}$ minerals after a similar conditioning time. This effect was not observed for the relatively pure minerals studied in the present investigation, in that the coverage of multilayer cupric hydroxamate was not noticeably less on relatively insoluble pseudomalachite than on chrysocolla. The coverage was probably more uniform on pseudomalachite than on chrysocolla, and the silica in the latter mineral probably remained in contact with the aqueous phase. XPS measurements on pure silica and $\mathrm{Cu}$ oxide minerals conditioned in the same hydroxamate solution and subsequently rinsed with water have 
confirmed that the collector does not adsorb on the surface of pure silica (Hope et al., 2010a). However, Herrera-Urbina and Fuerstenau (1987) have shown that quartz can be floated with n-octanohydroxamate collector when there are trace levels of metal ion impurities such as Fe in the flotation cell.

\section{Conclusions}

At low collector coverage, but in high collector concentration, the composition of the cupric hydroxamate nearest the solid/collector interface was confirmed as $\mathrm{Cu}$ (hydroxamate), rather than $\mathrm{Cu}$ (hydroxamate) $)_{2}$. On each mineral investigated, cupric hydroxamate multilayers were evident via Raman spectroscopy after substantial conditioning times in dilute hydroxamate solutions at $\mathrm{pH} 11$ and via XPS after short conditioning times in more concentrated collector solutions at $\mathrm{pH} 9.5$.

There is increasing evidence for the co-adsorption of some hydroxamic acid on surfaces conditioned at $\mathrm{pH} \sim 9.5$, but on all the conditioned and subsequently rinsed surfaces investigated, it has been a minor constituent. This suggests that it would be no more than a minor constituent at surfaces under the turbulent conditions in a flotation cell.

A substantial and uniform coverage of adsorbed cupric hydroxamate was identified at the surface of pure pseudomalachite after it had been conditioned at $\mathrm{pH}$ 9.5. Therefore, notwithstanding its lower solubility, pseudomalachite should be as floatable as malachite with n-octanohydroxamate collector at $\mathrm{pH} 9.5$.

XPS data for essentially pure chrysocolla conditioned in hydroxamate solution for periods of relevance to flotation established that multilayer patches of cupric hydroxamate were adsorbed at the mineral surface at $\mathrm{pH}$ 9.5. This observation is in agreement with the effectiveness of n-octanohydroxamate as a collector for chrysocolla.

The hydroxyls in the chrysocolla structure are distinct from simple metal hydroxyls in cupric hydroxide or malachite and do not appear to be significantly removed from the structure when the mineral copper reacts with hydroxamate collector. 


\section{Acknowledgements}

The Australian Research Council, and Axis House Ltd have provided support for this research project. Dr Ratan Chowdhury has assisted with preparation of purified n-octanohydroxamate compounds and his assistance with the project is gratefully acknowledged. Prof. P.A. Williams supplied the pseudomalachite sample for our investigation.

\section{References}

Anderegg, G., L’Eplattenier, F., Schwarzenbach, G. 1963. Hydroxamatkomplexe II. Die Anwendung der pH-Methode. Helv. Chim. Acta, 46, 1400-1408.

Crane, M.J., Sharpe, J.L., Williams, P. 2001. Formation of chrysocolla and secondary copper phosphates in the highly weathered supergene zones of some Australian deposits. Records of the Australian Museum, 53, 49-56.

Danilova, E.V., Otrozhdennova, L.A., Mikheeva I.V. 1975. Flotation of oxidized copper minerals by hydroxamic acids, Obogashchenie Rud, 20, 5-8.

Downs, R.T. 2006. The RRUFF Project: an integrated study of the chemistry, crystallography, Raman and infrared spectroscopy of minerals. Program and Abstracts of the 19th General Meeting of the International Mineralogical Association in Kobe, Japan. O03-13.

Farges, F., Benzerara, K., Brown, G.E. Jr., 2007.Chrysocolla redefined as spertiniite, AIP Conf. Proc., 882 (X-Ray Absorption Fine Structure (XAFS13)), 223-225.

Fuerstenau, D.W. 2007. A century of developments in the chemistry of flotation processing, In Froth Flotation: A Century of Innovation, eds. Fuerstenau, M.C., Jameson, G., Yoon, R.-H. SME, Littleton, CO, pp. 3-63.

Fuerstenau, D.W., Herrera-Urbina, R., McGlashan, D.W. 2000. Studies on the applicability of chelating agents as universal collectors for copper minerals. Int. J. Miner. Process., 58, 15-33.

Fuerstenau, D.W., Pradip. 1984. Mineral flotation with hydroxamate collectors, in: M.J. Jones, R. Oblatt (Eds.), Reagents in the Minerals Industry, Inst. Min. Metall., London, 161-168. 
Herrera-Urbina, R., Fuerstenau, D.W. 1987. The effect of trace metal ion impurities on the hydroxamate flotation of quartz. Int. J. Miner. Process., 21, 307-310.

Herrera-Urbina, R., Laskowski, J., Fuerstenau, D. 2010. A process for the flotation of chrysocolla. In Proc. XXV Int. Mineral Processing Congress, IMPC 2010. AusIMM, Melbourne, pp. 1959-1969.

Hope, G.A., Woods, R., Parker, G.K., Buckley, A.N., McLean, J. 2011. Spectroscopic characterization of copper acetohydroxamate and copper n-octanohydroxamate. Inorg. Chim. Acta, 365, 65-70.

Hope, G.A., Woods, R., Parker, G.K., Buckley, A.N., McLean, J. 2010a. A vibrational spectroscopy and XPS investigation of the interaction of hydroxamate reagents on copper oxide minerals. Miner. Eng., 23, 952-959.

Hope, G.A., Woods, R., Parker, G.K. 2010b. A SERS study of the interaction of n-octanohydroxamate with a copper electrode, ECS Transactions, 28, 15-25.

Lee, J.S., Nagaraj, D.R., Coe, J.E. 1998. Practical aspects of oxide copper recovery with alkyl hydroxamates, Miner. Eng., 11, 929-939.

Lee K., Archibald D., McLean J., Reuter M.A. 2009. Flotation of mixed copper oxide and sulfide minerals with xanthate and hydroxamate collectors. Miner. Eng., 22, 395-401.

Lindberg, B., Berndtsson, A., Nilsson, R., Nyholm, R., Exner, O. 1978. An ESCA investigation of ambident ions and tautomerism. $N$-cyanobenzamides and benzohydroxamic acids. Acta Chem. Scand. A, 32, $353-359$.

Losev, A., Kostov, K., Tyuliev, G. 1989. Electron beam induced reduction of $\mathrm{CuO}$ in the presence of a surface carbonaceous layer: and XPS/HREELS study. Surf. Sci., 213, 564-579.

McKeown, D.A., 1994. X-ray absorption spectroscopic study of copper in an amorphous copper silicate: chrysocolla, J. Non-Cryst. Solids, 180, 1-10.

Mosser, C., Mosser, A., Romeo, M., Petit, S., Decarreau, A. 1992. Natural and synthetic copper phyllosilicates studied by XPS. Clays Clay Miner., 5, 593-599. 
Numprasanthai, A., Hope, G.A., Buckley, A.N., Sheldon, G. 2011. The investigation of chrysocolla and malachite flotation using hydroxamates, this issue.

Parker, G.K., Hope, G.A., Woods, R., Numprasanthai, A., Buckley, A.N., McLean, J., 2012a. Investigation of the n Octanohydroxamate Reagent Interaction with the Surface of Oxide Copper Minerals and Copper Metal, In Yoon Symposium, 2011 SME Annual Meeting, ed. Young, C. SME, Denver, Colorado, p. Accepted 02/2011.

Parker, G.K., Buckley, A.N., Woods, R., Hope, G.A., 2012b. The Interaction of the flotation reagent, noctanohydroxamate, with sulfide minerals, this issue.

Peterson, H. D., Fuerstenau, M.C., Rickard, R. S., Miller, J. D. 1965. Chrysocolla flotation by the formation of insoluble surface chelates. Trans. Am. Inst. Min. Eng., 232, 388-392.

Pradip, Fuerstenau, D.W., The adsorption of hydroxamate on semi-soluble minerals, part I: adsorption on barite, calcite and bastnaesite. Colloids and Surfaces, 1983, 15, 137-146.

Prosser, A.P., Wright, A.J., Stephens, J.D. 1965. Physical and chemical properties of natural copper silicates that resemble chrysocolla. Trans. Inst. Min. Metall., 74 (1964-65) 233-258.

Raghavan, S., Fuerstenau, D.W. 1993. A lyometallurgical process for leaching copper from chrysocolla, in Proceedings Of The Fourth International Symposium On Hydrometallurgy (Salt Lake City, UT ) 283-297.

Raghaven, S., Fuerstenau, D.W. 1977. Characterization and pore structure analysis of a copper ore containing chrysocolla. Int. J. Miner. Process., 4, 381-394.

Rothenberg, A.S., Magliocco, L.G. 2002. Patent. Mineral collector compositions and processes for making and using same. Cytec Industries Inc US Patent 6,409,022.

RRUFF Database. 2011. Chrysocolla Raman, FT-IR and XRD reference data sets. http://rruff.info/Chrysocolla/R050053, accessed August 29, 2011.

Solomun, T., Schimanski, A., Sturm, H., Illenberger, E. 2004. Reactions of amide group with fluorine as revealed with surface analytics. Chem. Phys. Lett., 387, 312-316. 
van der Grift, C. J. G., Geus, J. W., Kappers, M. J., Maas, J. H. 1989. Characterisation of copper-silica catalysts by means of in situ diffuse reflectance infrared Fourier transform spectroscopy, Catal. Lett., 3, 159-168. 